\title{
A brutal case of physical child abuse
}

\author{
Rathnaweera RHAI ${ }^{1}$, Gunarathna EGUN ${ }^{2}$ \\ ${ }^{\prime}$ Department of Forensic Medicine, Faculty of Medicine, University of Ruhuna, Galle, Sri Lanka. \\ ${ }^{2}$ Base Hospital, Balapitiya, Sri Lanka.
}

Correspondence: Dr. R.H.A.I. Rathnaweera

e-mail: ajithrathnaweera@gmail.com

Dttps://orcid.org/0000-0002-7418-2981

\section{Introduction}

The precise definition of child abuse varies from countries to cultures in given periods of time. However, in 1999, the World Health Organization formulated the following definition: "Child abuse or maltreatment constitutes all forms of physical and or emotional ill-treatment, sexual abuse, neglect or negligent treatment or commercial or other exploitation, resulting in actual or potential harm to the child's health, survival, development or dignity in the context of a relationship of responsibility, trust or power" (1). Further to that, the physical child abuse is defined as "That which results in actual or potential physical harm from an interaction or lack of an interaction, which is reasonably within the control of a parent or person in a position of responsibility, power or trust. There may be single or repeated incidents" (2).

Even though the act of child abuse has been a known occurrence throughout the history, it has become a significant social problem only in the recent past. According to United Nations International Children's Emergency Fund (UNICEF, 2012) report on the epidemiology, more than one in four children worldwide have experienced severe and frequent physical abuse (3). According to some other studies, it is estimated that, nearly a quarter of adults $(22.6 \%)$ have suffered physical abuse as a child, throughout the world (4). Approximately 2.9 million cases of child abuse are reported every year in the United States and the boys $(48.5 \%)$ and girls $(51.2 \%)$ become victims at nearly the same rate. It is assumed that in the United States, more than 4 children die from child abuse and neglect on a daily basis (5). According to
UNICEF, prevalence rate of child abuse in low and lower middle-income countries across the East Asia and Pacific regions is around $17-35 \%(5)$.

The actual incidence of child abuse in Sri Lanka is not known and it is known to vary from area to area. According to available literature, child abuse in Sri Lanka is a well-recognized social problem (4). According to a study done in the Northern Sri Lanka, $83.8 \%$ of the studied children reported a life time history of some form of abuse (6). In another study done in Sri Lanka, the overall prevalence of childhood physical abuse in the studied sample was $45.4 \%$ (4). In a study done in Southern province of Sri Lanka, prevalence of physical child abuse among male and female children were $22.4 \%$ and $15.7 \%$ respectively (7). Fernando \& Karunasekera (2009) reported 44\% physical abuse among the state university students during their childhood (8). According to statistics of the National Child Protection Authority of Sri Lanka, in 2019 they had received 2,342 complaints regarding cruelty to children (9). The case under discussion is an unfortunate event where a female child, who was handed over to a relative to look after and to send to school due to financial difficulties, was kept as a domestic servant and subsequently subjected to physical abuse.

\section{Case presentation}

An eight-year old girl, who was living with her aunt for the last three years, was admitted to a tertiary care hospital with a history of an accidental fall. She was living with her aunt due to financial difficulties faced by her family since her father 
abandoned them. She was handed over to her aunt by her mother to be looked after and to be sent to school. As there were some unexplainable injuries present over the body and the incompatible nature of the history, she was referred for a medico-legal examination.

She was depressed in mood and not willing to communicate. On questioning, she initially mentioned about an accidental fall while climbing a tree. Once a rapport was developed, she revealed a totally different story. According to her, she was continuously being abused physically by her uncle during the last 3 years. She revealed that she was hanged by her wrists or ankles on the roof and then was beaten up with clubs and a cane. She also mentioned that sometimes her uncle used a hot iron rod and fire sticks to burn her back and limbs when she was caught playing outside with her cousins. Her genitals were burnt with a hot iron rod very recently because she wet her bed on sleep. She was lifted and thrown away at times causing fractures to her bones. Although the son and daughter of her aunt were sent to school, she was kept at home as a domestic servant. She had to do all the cleaning of the house as well as washing all the clothes. She was not given adequate food or clothing and her healthcare and well-being was found to be neglected. Even though she was not sexually abused by her uncle, she was repeatedly scolded and insulted both by her aunt and her uncle, subjecting her to a serious form of emotional abuse. She was threatened with abandonment, causing injury and even death by her uncle.

On examination, she was an averagely built moderately nourished girl without the development of secondary sexual characteristics. She had frozen awareness and eye avoidance. She had multiple oral hygienic issues. There were fresh, partially healed and old healed injuries over several parts of her body. Multiple fresh contusions were observed over the outer aspect of her right upper arm. Recent fractures were observed over mid shaft of the right femur and the left superior pubic rami of the pelvis (Figure 01). Tractions were found to be applied over her right lower limb due to the fracture femur (Figure 02). Partially healed burn injuries were noted over her perineal area with the involvement of her external genitalia (Figure 03).
Her hymen was found to be intact with no evidence of sexual abuse. Healed abrasions were noted over the anterior and medial aspects of the left lower leg and ankle (Figure 04) and over the medial and lateral aspects of the left lower forearm. Multiple scaring due to healed burn injuries were noted over the back, front of the right thigh (Figure 05) and over the buttocks (Figure 06). Multiple partially healed and healed abrasions were noted over the abdomen (Figure 07) and over the back. Her injuries were attended accordingly and a multidisciplinary approach was made for further management. According to the Paediatrician, she was under-nourished and needed further treatment. According to the psychiatrist, she was depressed and needed further follow up. The fractures and soft tissue injuries were dealt with by the general surgeon and the Orthopaedic surgeon. Other than the fractures mentioned above, no other recent or old fractures were identified in the skeletal survey. A case conference was held with the participation of all stake holders to decide what should be done regarding the custody of the child. At the end, it was decided to hand over the child back to her mother once the legal procedures are over. The probation officers agreed to follow up the child and the divisional secretary's office agreed to provide the necessary facilities to start schooling for the child.

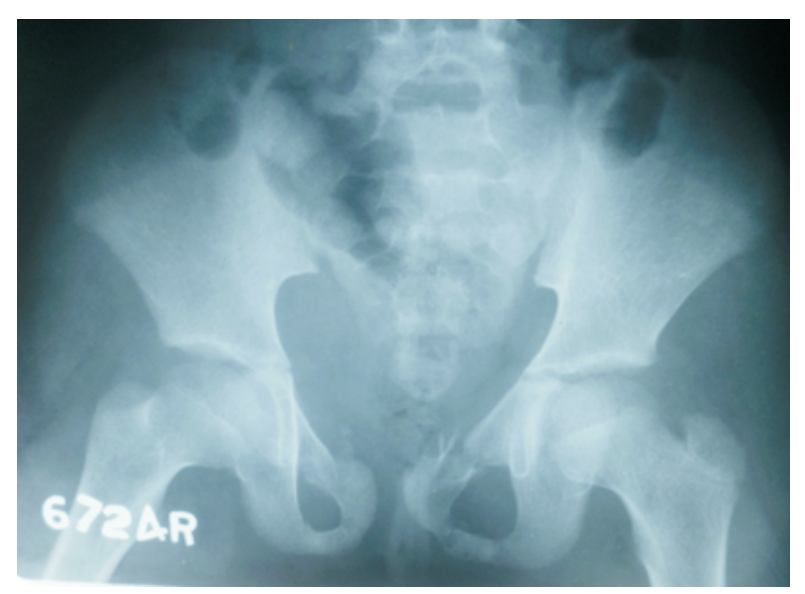

Figure 1: Fracture of the left superior pubic rami 


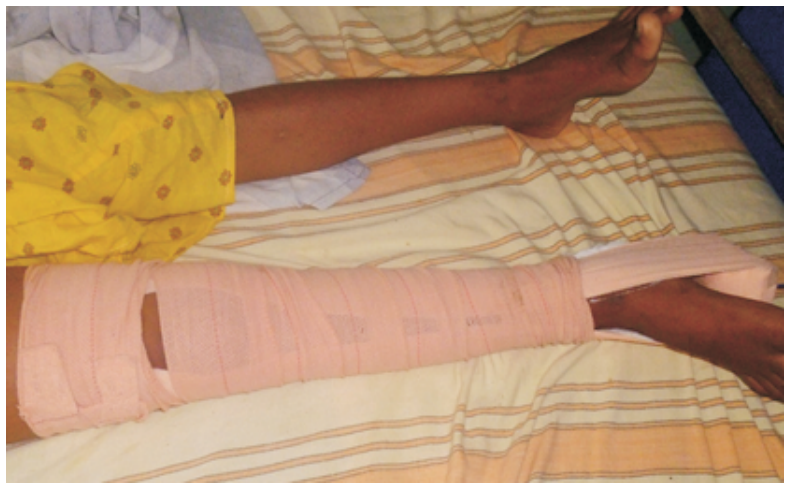

Figure 2: Tractions applied over right lower limb

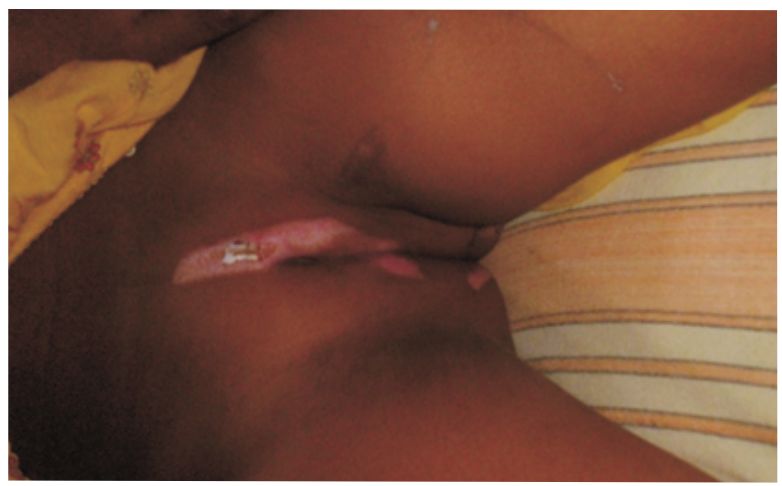

Figure 3: Partially healed burns in the perineum

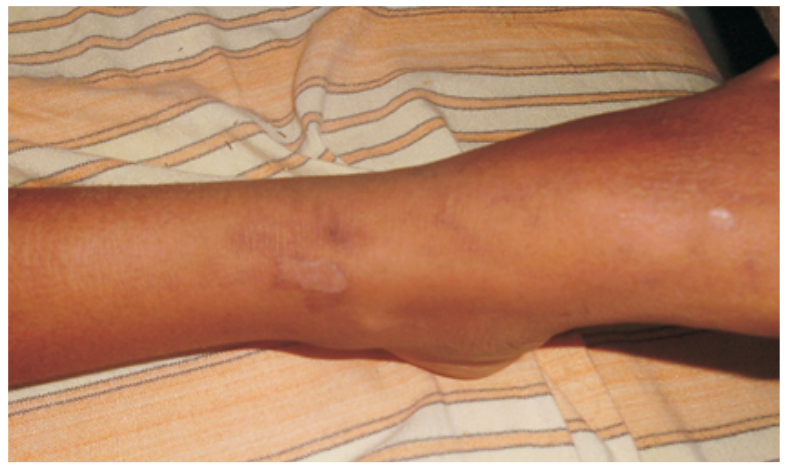

Figure 4: Healed abrasions over left lower leg and ankle

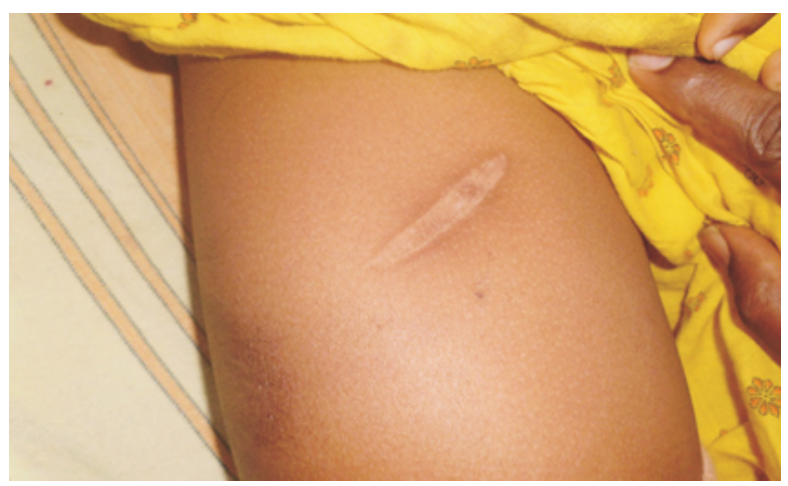

Figure 5: Healed burn injury over right thigh

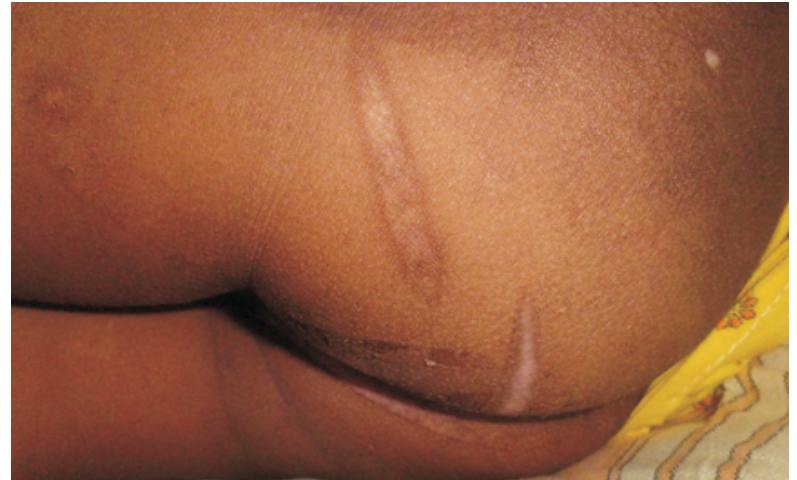

Figure 6: Healed burn injuries over buttock

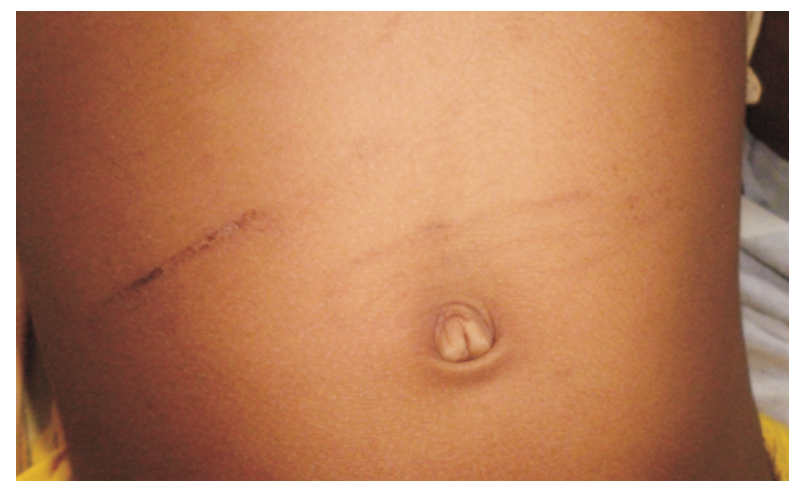

Figure 7: Partially healed and healed abrasions over the abdomen

\section{Discussion}

Childhood is usually considered as a time to be carefree, innovative and be happy. However, for thousands of children, this may not be true as violence has taken over their lives. It is believed that approximately $75 \%$ of the child abuse cases may be missed by the health care professionals due to their failure to recognize signs of abuse (10). This is critical in the management as this missed opportunity to intervene may lead to repeated abuse which may ultimately be fatal to the innocent victim. Some of the identified warning signs of physical abuse in children include; (i) frequent injuries or unexplained bruises, welts, or cuts (ii) being always watchful and on alert, as if waiting for something bad to happen (iii) injuries appear to have a pattern such as marks from a hand or belt (iv) shying away from touch, flinches at sudden movements, or seems afraid to go home (v) wearing inappropriate clothing to cover up injuries, such as long-sleeved shirts on hot days (10). In this instance, the health care workers were on alert to the unusual 
pattern of injuries present and they have taken necessary actions to report it. This has led to the correct management of the child, with the handing over of the child's custody back to the mother.

Physical abuse maybe the result of deliberate attempt to hurt the child or to discipline the child (10). According to literature, most abusers are family members or those who are close to the family and the abuse by strangers are very rare (10). The usual perpetrator for physical child abuse is the parents followed by teachers (4). In a study done in Egypt, $37 \%$ reported being beaten or tied up by their parents (11). In another study done in Korea, $45 \%$ confirmed that they were beaten or whipped by their parents (12). In one of the recent studies conducted in Sri Lanka, only $3.4 \%$ were found to be physically abused by a male relative (4). As this case pointed out, even though the incidence is low, physical abuse by relatives do occur and a close attention is needed to prevent such activity.

The majority of children who are physically abused are younger than 3 years and the infants and preschoolers are supposed to be at a greater risk (8). It is believed that as a child ages, the risk of abuse decreases (7). In a study done in Northern Sri Lanka, children below 5 years of age were the commonest age group subjected to physical abuse (13). In the case discussed here, the victim was an eight-year-old girl. This is a good example for the fact that, irrespective of the age, children can face severe forms of physical abuse. According to literature, beating a child with an object such as cane or clubs were the commonest method used for physical abuse followed by hitting or punching $(4,11)$. Burning with heated object was found to be as low as less than $2 \%(5,11)$. In this instance also, this child was repeatedly assaulted using a cane and clubs. Moreover, she was burnt several times using a heated iron rod and fire sticks, which is an uncommon occurrence according to literature.

Contusions are the most common type of injury present in the victims of physical abuse (11). Injuries due to sharp force are relatively rare. In this case also fresh contusions were identified over the outer aspect of the upper arm. No sharp force injuries were seen among the injuries present on her body. Injuries caused by burns are a recognised category in physical child abuse. It is estimated that approximately $10 \%$ to $25 \%$ of pediatric burns result from abuse (14). The most common cause for childhood burns is scalds due to hot liquids followed by contact burns resulting from direct contact with a heated object (15). Inflicted contact burns tend to cause more sharply defined pattern with a recognizable shape whereas accidental contact burns tend to be less well demarcated, because of the reflex action of the child (15). In this instance, multiple clearly demarcated partially healed and healed burn injuries were identified over her buttock, thigh and perineum. The clearly demarcated patterns present were highly suggestive of deliberate application of a heated object. Multiple fractures or fractures in different stages of healing in a child always raise the possibility of an abuse (14). Metaphyseal lesions, posterior rib fractures, scapular fractures and fractures of spinous processes are some of the fractures which are highly suggestive of abuse (14). Fractures with a moderate specificity for abuse include epiphyseal separations, vertebral body fractures and subluxations, digital fractures, and complex skull fractures (14). In this instance, there were fractures involving the right femur shaft and the pelvis. Although the skeletal survey did not reveal any old fractures, presence of multiple fractures was highly suggestive of abuse.

Some of the injuries inflicted in physical child abuse may not be visible to the untrained eye. All regions of the body are needed to be thoroughly examined to avoid such mistakes. Obscure sites for inflicted injuries include the ears, especially the posterior aspects, the neck and angle of the jaw, scalp, and the frenula of the lip and tongue (14). In comparison to accidental injuries, inflicted injuries tend to occur in sites away from bony prominences such as neck, buttocks, trunk, hands and upper arm (14). In this case, no obscure injury was identified after a thorough examination. However, most of the injuries identified were present at sites away from bony prominences, such as buttock, indicating the possibility of physical abuse.

According to the right of children to free and compulsory education act, 2009 (16), every child of the age of six to fourteen years shall have the right to free and compulsory education in a neighborhood school till the completion of his or her elementary education. However, the upper limit 
of compulsory education age was increased to sixteen years in the year 2016 (17). In this instance this child was not given education for the last 3 years, which was a clear violation of her rights. On the other hand, employment of women, young persons and children act (18), prohibits employment of children under the age of 14 years except in the following circumstances; by his parents or guardian in light agricultural or horticultural work or similar work carried on by members of the same family before the commencement of regular school hours or after the close of school hours. According to this act also, employing a child below 14 years for work depriving education rights is an offence. Therefore, other than physical child abuse, the assailants can be charged for two additional offences.

In conclusion, this child gave a history of assault with clubs and a cane after tying her wrists and ankles with a rope. Compatible injuries were observed over her wrists, ankles, abdomen and over her back. She also gave a history of repeated burning of her body with a heated iron rod and fire sticks. Compatible injury patterns were observed over her genitals, limbs and over the back. She had multiple long bone fractures and a pelvic fracture making her injuries grievous. Injuries found on her body were of different stages of healing ranging from very recent fresh injuries to old healed scars. This was a clear indication of the repeated abuse experienced by this girl over the past few years. Even though there were burns over her genitals, there was no evidence of sexual abuse. She was deprived of schooling and she was kept as a domestic servant, both of which are punishable offences together with physical child abuse. Although prevention of child abuse has been on focus among various professional groups, cases of this magnitude still surface from time to time. The awareness regarding these issues among the general public as well as the health care providers are the need of the day to minimise these unfortunate incidences in the future.

Written informed consent was obtained from the guardian for publication of this case report with photographs.

\section{References}

1. Report of the Consultation on Child Abuse Prevention, 2931 March 1999. [Internet]. WHO, Geneva. Geneva, World Health Organization, 1999 [cited 2020 May 05]. Available from: https://apps.who.int/iris/handle/10665/65900

2. United Nations Children's Fund, Violence against Children in East Asia and the Pacific: A Regional Review and Synthesis of Findings, Strengthening Child Protection Series. [Internet]. No. 4, UNICEF EAPRO, Bangkok, 2014. [cited 2020 May 05]. Available from: https://www.unicef.org/eap/media/2901/file/violence.pdf

3. Protecting children from violence, exploitation and abuse. UNICEF (2012). [Internet] from Bangkok: UNICEF EAPRO, 2012 [Cited 2020 May 02]. Available from: https://www. unicef.org/protection/57929_57972.html.

4. Chandraratne NK, Fernando AD, Gunawardena A. Physical, sexual and emotional abuse during childhood: Experiences of a sample of Sri Lankan Young adults. Child Abuse \& Neglect, 2018; 81: 214-224.

5. Global status report on violence prevention 2014. [Internet]. World Health Organization. Geneva. 2014. [cited 2020 May 05]. Available from: http:// www. who.int/ violence_injury_prevention/violence/status_report/ 2014/en/

6. Sriskandarajah V, Neuner F, Catani C. Predictors of violence against children in Tamil families in northern Sri Lanka. Social Science \& Medicine, 2015 December; 146: 257-265.

7. Perera B, Osbyte T, Ariyananda PL, Lelwala E. Prevalence and correlates of physical and emotional abuse among late adolescents. Ceylon Medical Journal, 2009; 54(1): 10-15.

8. Fernando AD, Karunasekara W. Juvenile victimization in a group of young Sri Lankan adults. Ceylon Medical Journal, 2009; 54(3): 80-84

9. Number of complaints reported to "1929" child help line from $01^{\text {st }}$ Jan 2019 to $31^{\text {st }}$ Dec. 2019. [Internet]. National Child Protection Authority. [cited 01/05/2020]. Available from: http://www.childprotection.gov.lk/wp-content/ uploads/2018/02/2020.2.24-1929-complaint-data-toweb.pdf

10. Kudagammana ST. Defining and comprehending child abuse at present times - an appraisal. Sri Lanka Journal of Forensic Medicine, Science \& Law, 2010;1(2): 28-32. 
11. Youssef RM, Attia MS, Kamel MI. Children experiencing violence: parental use of corporal punishment. Child Abuse \& Neglect, 1998;22: 959973.

12. Hahm H, Guterman N. The emerging problem of physical child abuse in South Korea. Child Maltreatment, 2001; 6 : 169-179.

13. Sathiadas MG, Mayoorathy S, Varuni K, Ranganathan SS Child Abuse in Northern Sri Lanka. Indian J Pediatr, 2017; 84(2): 128-133.

14. Hornor G. Physical Abuse: Recognition and Reporting. JPediatr Health Care, 2005; 19: 4-11.

15. Peck MD, Priolo-Kapel D. Child abuse by burning: A review of the literature and an algorithm for medical investigations. The Journal of Trauma Injury, Infection, and Critical Care, 2002; 53: 1013-1021.
16. The right of children to free and compulsory education act, 2009. [cited 2020 May 05] Available from: http://www.rplegalindia.com/wp-content/themes/ rp-legal/pdf

17. The Evolution of Education in Sri Lanka. 2017. [cited 2020 May 0]. Available from; https://roar.media/english/life/ sponsored/the-evolution-of-education-in-sri-lanka/

18. Employment of women, young persons and children act 1956. [Internet]. [cited 2020 May 05]. Available from: https://www.lawnet.gov.lk/1947/12/31/employment-ofwomen-young-persons-and-children-3/ 